\title{
Profibrotic agents for venous malformations?
}

DOI: $10.1111 /$ bjd.13164

\section{ORIGINAL ARTICLE, p 242}

Venous malformations (VMs) are common vascular anomalies affecting $1-4 \%$ of the population. ${ }^{1,2}$ These slow-flowing, abnormally shaped and dilated veins ${ }^{3}$ can be superficial or deep, localized or diffuse, and may occur in multiple areas. ${ }^{4}$ Histologically, VMs appear irregular with a flattened endothelium and a thin basement membrane. ${ }^{1,2}$ All VMs are present at birth, but often manifest clinically between infancy and early adulthood. VMs grow as children develop, and are associated with a wide range of symptoms based on their localization and size. Most patients experience localized intravascular coagulopathy that may lead to thrombosis and pain. Symptoms can be exacerbated by trauma or altered hormonal states (puberty, pregnancy). ${ }^{2,5}$ In larger lesions, the associated thrombophilic profile of VMs also predisposes patients to deep venous thrombosis and pulmonary embolism. Management of VMs includes pressure garments, pain medication and prophylactic heparin during states of increased risk for thrombosis (pregnancy, prolonged bed rests, surgery). Treatments are indicated if a lesion causes severe pain, functional impairment or aesthetic concerns, and include intervention radiology with sclerotherapy or surgical resection. Importantly, surgical resection is contraindicated if VMs interact with critical neurovascular structures.

The efficacy of sclerotherapy depends on the sclerosant used. ${ }^{2}$ Most sclerosants used for VMs (ethanol, or surfactants such as sodium tetradecylsulfate or polidocanol) trigger necrosis-mediated vessel destruction. ${ }^{2}$ Ethanol is the most efficient agent but also the most toxic. Side-effects of sclerotherapy, which include skin necrosis and nerve injury at the site of injection, can affect up to $30 \%$ of treated patients. ${ }^{2}$ With the choice of sclerosant being the most important variable for complications, research aimed at identifying efficient therapies with fewer side-effects is of great clinical interest.

In this issue of the British Journal of Dermatology, Ren et al. sought to gain insight into the pathology of VMs by analysing the expression pattern of CCN proteins in human VM samples. ${ }^{6} \mathrm{CCNs}$ form a family of six proteins named after their first three members [Cyr61 is CCN1; connective tissue growth factor is CCN2; and nephroblastoma overexpressed (Nov) is CCN3]. CCNs are multimodular, matricellular proteins involved in a plethora of biological functions encompassing embryogenesis, inflammation, fibrosis and tumorigenesis. ${ }^{7,8}$ Ren et al. found that CCN2 levels are reduced in VMs compared with normal skin blood vessels. The authors also show colocalization of $\mathrm{CCN} 2$ with the profibrotic transforming growth factor (TGF) $\beta$ in human cutaneous blood vessels, and underscore a significant correlation between reduced CCN2 protein and reduction of TGF $\beta$ and perivascular $\alpha$-smooth muscle actin levels in VMs. These results, suggestive of an association between the TGF $\beta / C C N 2$ pathway and vascular integrity in human skin, are consistent with previous work identifying CCN2 as a critical endothelial organizer, a mediator of vascular basement membrane production in mice, ${ }^{9}$ and a downstream effector of TGF $\beta$-mediated extracellular matrix production. $^{10}$ Ren et al. further demonstrate that TGF $\beta$ or CCN2 stimulates extracellular matrix production by endothelial cells in vitro, and that these effects can be mimicked by the sclerotic agent bleomycin A5. Interestingly, recent clinical studies have demonstrated the efficacy of bleomycin for sclerotherapy of $\mathrm{VMs}^{11,12}$ and other vascular anomalies. ${ }^{13}$ In all, the study by Ren et al. proposes an underlying mechanism for loss of blood vessel integrity in VMs, and suggests that therapeutic strategies aimed at restoring CCN2 and/or extracellular matrix production in VMs should receive careful consideration.

\section{Conflicts of interest}

None declared.

Department of Dermatology, University of

L. Ritití Michigan, 6447 Medical Science Bldg. I,

1301 E. Catherine St, Ann Arbor, MI

48109, U.S.A.

E-mail: LRittie@umich.edu

\section{References}

1 Garzon MC, Huang JT, Enjolras O, Frieden IJ. Vascular malformations: Part I. J Am Acad Dermatol 2007; 56:353-70.

2 Legiehn GM, Heran MK. Venous malformations: classification, development, diagnosis, and interventional radiologic management. Radiol Clin North Am 2008; 46:545-97, vi.

3 Marler JJ, Mulliken JB. Vascular anomalies: classification, diagnosis, and natural history. Facial Plast Surg Clin North Am 2001; 9:495-504.

4 North PE, Mihm MC Jr. Histopathological diagnosis of infantile hemangiomas and vascular malformations. Facial Plast Surg Clin North Am 2001; 9:505-24.

5 Hill RA, Pho RW, Kumar VP. Resection of vascular malformations. J Hand Surg Br 1993; 18:17-21.

6 Ren JG, Chen G, Zhu JY et al. Downregulation of the transforming growth factor- $\beta /$ connective tissue growth factor 2 signalling pathway in venous malformations: its target potential for sclerotherapy. Br J Dermatol 2014; 171:242-51.

7 Perbal B. CCN proteins: multifunctional signalling regulators. Lancet 2004; 363:62-4.

8 Jun JI, Lau LF. Taking aim at the extracellular matrix: CCN proteins as emerging therapeutic targets. Nat Rev Drug Discov 2011; 10:945-63. 
9 Hall-Glenn F, De Young RA, Huang BL et al. CCN2/connective tissue growth factor is essential for pericyte adhesion and endothelial basement membrane formation during angiogenesis. PLOS ONE 2012; 7:e30562.

10 Lipson KE, Wong C, Teng Y, Spong S. CTGF is a central mediator of tissue remodeling and fibrosis and its inhibition can reverse the process of fibrosis. Fibrogenesis Tissue Repair 2012; 5 (Suppl. 1):S24.

11 Jin Y, Lin X, Li W et al. Sclerotherapy after embolization of draining vein: a safe treatment method for venous malformations. J Vasc Surg 2008; 47:1292-9.

12 Spence J, Krings T, TerBrugge KG, Agid R. Percutaneous treatment of facial venous malformations: a matched comparison of alcohol and bleomycin sclerotherapy. Head Neck 2011; 33:125-30.

13 Yang Y, Sun M, Ma Q et al. Bleomycin A5 sclerotherapy for cervicofacial lymphatic malformations. J Vasc Surg 2011; 53:150-5.

\section{Epidemiology of hand eczema from adolescence to adulthood}

DOI: $10.1111 /$ bjd.13182

\section{ORIGINAL ARTICLE, p 313}

In their original article in the current issue of BJD, Moertz et al. ${ }^{1}$ present findings from a 15 -year follow-up of The Odense Adolescence Cohort Study on Atopic Diseases and Dermatitis (TOACS), in which 1271 adolescents with a mean age of 14 years had originally been enrolled. A response rate of $75 \%$ was achieved in the questionnaire follow-up. Keeping loss to follow-up low is important for any prospective cohort study to avoid the reporting of biased results. The study is important because it is the first to report on the epidemiology of hand eczema (HE) from adolescence to adulthood in an unselected population.

The first aim of the study was to estimate the incidence of HE from adolescence to adulthood, i.e. the number of newly occurring cases of $\mathrm{HE}$ in the observation period. An incidence rate of 8.8 per 1000 persons per year was estimated. The period from adolescence to adulthood is critical for the development of HE, and it is this period in which occupational choices are made and some young adults will choose occupations carrying an elevated risk of developing HE. Previous studies reporting incidence data have either been limited to adult populations ${ }^{2,3}$ or have followed up selected populations of adolescents such as car industry apprentices. ${ }^{4}$ The second aim was to estimate HE prevalence, which is important in order to understand the population burdened with the disease. The point, 1year-period and lifetime prevalence rates were estimated at $7 \cdot 1 \%, 14 \cdot 4 \%$ and $23 \cdot 0 \%$, respectively. A review of epidemiological studies on HE, including seven population-based studies, reported lower estimates for incidence ( 5.5 cases per 1000 person-years) and point, 1-year-period and lifetime prevalence rates $\left(4.0 \%, 10 \%\right.$ and $15 \%$, respectively). ${ }^{5}$ This reflects the younger age group investigated in TOACS and demonstrates that the onset and burden of HE are particularly high in adolescents and young adults. Both the TOACS follow-up and the review found incidence and prevalence estimates to be substantially higher in women than men.

The third aim of Moertz et al. was to investigate risk factors for $\mathrm{HE}$ in the past year in the young adults who were followed up, applying logistic regression modelling. Studying risk factors for HE is important in order to identify those modifiable factors that act in concert with constitutional factors, but are therefore amenable to prevention and/or early treatment. The significant positive associations of childhood atopic dermatitis with HE in adolescence ${ }^{3,6}$ and taking care of small children with $\mathrm{HE}^{,}{ }^{7}$ as well as the lack of association of nickel sensitization and $\mathrm{HE},{ }^{6,8}$ have been previously reported. The lack of association of HE with smoking seems to contradict previous findings, ${ }^{9,10}$ but the effects of smoking seem to depend on exposure level and may also be restricted to certain subtypes of HE. Although the clinical examination included in the study by Moertz et al. showed that most cases of HE that were examined were actually mild, it is striking that the chances of sick leave, disability pension or rehabilitation were found to be almost threefold increased with HE, pointing to the potentially severe consequences of HE already in young adults.

\section{Conflicts of interest}

None declared.

Institute of Epidemiology and Preventive

C. Apfelbacher

Medicine, Faculty of Medicine, University of

Regensburg, Regensburg, Germany

E-mail: christian.apfelbacher@klinik.uni-regensburg.de

\section{References}

1 Moertz CG, Bindslev-Jensen C, Andersen KE. Hand eczema in The Odense Adolescence Cohort Study on Atopic Diseases and Dermatitis (TOACS): prevalence, incidence and risk factors from adolescence to adulthood. Br J Dermatol 2014; 171:313-23.

2 Meding B, Jarvholm B. Incidence of hand eczema - a populationbased retrospective study. J Invest Dermatol 2004; 122:873-7.

3 Lerbaek A, Kyvik KO, Ravn $\mathrm{H}$ et al. Incidence of hand eczema in a population-based twin cohort: genetic and environmental risk factors. Br J Dermatol 2007; 157:552-7.

4 Apfelbacher CJ, Radulescu M, Diepgen TL, Funke U. Occurrence and prognosis of hand eczema in the car industry: results from the PACO follow-up study (PACO II). Contact Dermatitis 2008; 58:322-9.

5 Thyssen JP, Johansen JD, Linneberg A, Menné T. The epidemiology of hand eczema in the general population - prevalence and main findings. Contact Dermatitis 2010; 62:75-87.

6 Josefson A, Farm G, Magnuson A, Meding B. Nickel allergy as risk factor for hand eczema: a population-based study. Br J Dermatol 2009; 160:828-34. 